\title{
Barriers to the recognition and reporting of occupational asthma by Canadian pulmonologists
}

\author{
Anu Parhar MD ${ }^{1}$, Catherine Lemiere MD MSc${ }^{2}$, Jeremy R Beach MBBS MD ${ }^{1}$
}

\begin{abstract}
A Parhar, C Lemiere, JR Beach. Barriers to the recognition and reporting of occupational asthma by Canadian pulmonologists. Can Respir J 2011;18(2):90-96.
\end{abstract}

BACKGROUND: Occupational asthma is a common, but probably under-recognized problem.

OBJECTIVE: To identify the factors that suggest work-related asthma when a pulmonologist encounters an adult patient with new-onset asthma, and to identify the barriers to recognizing and reporting such cases.

METHODS: A postal questionnaire was sent to all pulmonologists in Canada. The questionnaire asked participants to respond to several questions about recognizing, diagnosing and reporting occupational asthma. Answers were scored using visual analogue scales.

RESULTS: A total of 201 eligible responses were received from 458 pulmonologists. Pulmonologists identified that the most important factor in initially considering the role of work in occupational asthma was having seen others affected at the same workplace, or exposed to the same agent. Important perceived barriers to considering a diagnosis of occupational asthma were physicians' low awareness, lack of knowledge and time. The most important barriers to reporting cases were the pulmonologists' perceived patient concerns regarding job security and income. Quebec pulmonologists generally perceived barriers to recognizing and reporting occupational asthma to be less important, and believed that the use of specific inhalation challenge was more important in considering a diagnosis.

CONCLUSIONS: Pulmonologists most readily recognized occupational asthma caused by a substance or process that they previously encountered as a possible cause of asthma. Time constraints and knowledge may hamper their ability to recognize occupational asthma. Concerns regarding the effect of the diagnosis on the patient's job and income may discourage reporting.

Key Words: Asthma; Occupational; Work-related; Workers' compensation

$\mathrm{C}$ ausation is a complex concept that has no universally accepted definition. Nonetheless, the issue of causation and the recognition of work relatedness can have important implications. Within Canada and many other jurisdictions around the world, if an injury or illness is determined to be caused or contributed to by work, then the Workers' Compensation Board/provincial workers' compensation system (WCB) becomes wholly or partially responsible for many components of care, rehabilitation and compensation. In the event that an injury is not deemed to be work related, other agencies then bear the responsibility of providing these same services. In addition, statistics produced by the WCB are frequently used as a measure of incidence of work-related disease and, therefore, affect the emphasis placed on prevention. Consequently, the identification of an injury or illness as being caused by work or the workplace has important implications for the affected individual and for society as whole.

A physician's opinion is often a crucial first step in triggering recognition of work relatedness. Once this first step has occurred, a physician's opinion carries considerable weight in the WCB process. Deciding whether an injury or illness is caused by work may be complex (1-5) and, in cases for which physicians' opinions are unclear or conflict with the issue of causation, there may be considerable delays in determining entitlement while the medical issues are ascertained. Furthermore, even when a physician determines that an illness or

\section{Les obstacles au dépistage et à la déclaration de l'asthme professionnel par les pneumologues canadiens}

HISTORIQUE : L'asthme professionnel est un problème courant, mais probablement sous-reconnu.

OBJECTIF : Repérer les facteurs évocateurs d'asthme liés au travail lorsqu'un pneumologue rencontre un patient adulte atteint d'asthme de novo, et déterminer les obstacles au dépistage et à la déclaration de ces cas.

MÉTHODOLOGIE : Tous les pneumologues du Canada ont reçu un questionnaire par la poste. On y demandait de répondre à plusieurs questions sur le dépistage, le diagnostic et la déclaration de l'asthme professionnel. Les réponses étaient cotées au moyen d'échelles analogiques visuelles. RÉSULTATS : Au total, 458 pneumologues ont expédié 201 réponses admissibles. Ils ont indiqué que le principal facteur pour envisager initialement le rôle du travail dans l'asthme professionnel était d'avoir observé d'autres cas dans le même milieu de travail ou d'autres cas exposés au même agent. Les obstacles importants perçus pour envisager un diagnostic d'asthme professionnel étaient le peu de sensibilisation, le manque de connaissances et le manque de temps des médecins. Les principaux obstacles pour déclarer des cas étaient les inquiétudes que percevaient les pneumologues de la part des patients à l'égard de la sécurité d'emploi et le revenu des patients. En général, les pneumologues québécois percevaient les obstacles au dépistage et à la déclaration de l'asthme professionnel comme moins importants et pensaient que le recours à une épreuve d'inhalation spécifique importait davantage pour envisager un diagnostic.

CONCLUSIONS : Les pneumologues dépistent plus rapidement l'asthme professionnel attribuable à une substance ou un processus qu'ils ont déjà observé comme cause possible d'asthme. Les contraintes de temps et leurs connaissances peuvent nuire à leur capacité de dépister l'asthme professionnel. Les inquiétudes quant à l'effet du diagnostic sur l'emploi et le revenu du patient peuvent décourager la déclaration.

injury is caused by or contributed to by work, they may not report it to the WCB. For mesothelioma, which should be more easily recognized as work-related than many other illnesses and injuries, less than one-half of all cases in some provinces may be reported $(6,7)$.

Previous research in the United Kingdom (8) has attempted to identify the factors that contribute to a physician deciding whether an injury or illness is work related; however, this study only addressed musculoskeletal disorders. The factors identified to be most important were 'history of onset in relation to workplace changes' and 'symptoms consistent with workplace exposure'. However, relating musculoskeletal disorders to a specific workplace incident may be more straightforward than identifying a link with a disease such as asthma.

Occupational asthma is the most common type of work-related respiratory disease, and represents up to $20 \%$ of all new-onset adult asthma cases $(9,10)$. Furthermore, there is good evidence that early recognition of a workplace cause of injury or illness may be important in prognosis (11). Despite this, occupational asthma is likely still under recognized and under reported (12). The aim of the present study was to identify the factors that suggest work-related asthma when a pulmonologist encounters an adult patient with new-onset asthma. In addition, we sought to identify factors that possibly acted as barriers to the reporting of such cases once they were recognized.

${ }^{1}$ Department of Medicine, University of Alberta, Edmonton, Alberta; ${ }^{2}$ Department of Medicine, University of Montreal, Montreal, Quebec Correspondence: Dr Jeremy R Beach, Occupational Medicine Program, University of Alberta, 5-30 University Terrace,

8303112 Street, Edmonton, Alberta T6G 1K4. Telephone 780-492-6291, fax 780-492-9677, e-mail jeremy.beach@ualberta.ca 


\section{METHODS}

A listing of all specialist pulmonologists in Canada was obtained from the Royal College of Physicians and Surgeons of Canada, and the Collège des Médecins du Québec. The websites of all provincial colleges of physicians and surgeons in Canada were checked to verify that the pulmonologists were listed as active in practice and that they did not exclusively see pediatric patients.

All pulmonologists were sent a postal questionnaire (Appendix 1) asking for their opinion on factors that, for a given case of new-onset adult asthma would be associated with the following:

- Make them initially consider occupational factors as a possible cause of asthma;

- Strengthen the impression for a given case that work might be relevant;

- Be significant barriers to considering a diagnosis of occupational asthma;

- Represent significant barriers to diagnosing a case of occupational asthma; and

- Be important barriers to reporting a case to the WCB.

Participants were also asked which of a series of diagnostic tests they would use in addition to a symptom and work history before making a diagnosis of occupational asthma.

A series of possible answers to each question was offered, and participants were asked to rate the importance of each answer from 'not at all' to 'extremely important' using a $100 \mathrm{~mm}$ visual analogue scale. For example, if a respondent believed that a patient's opinion about the work relatedness of their asthma was very important to their considering occupational factors in the diagnosis, they would mark the line $90 \mathrm{~mm}$ from the left side of the scale, which corresponded to a score of 90. Completed questionnaires were returned by mail and the data were anonymized before being entered into a database. A maximum of two reminders were sent.

All statistical analyses were performed using SPSS version 16 (IBM Corp, USA) and Minitab release 15 (Minitab Inc, USA). Mean and median scores for answers to each question were calculated. Visual analogue scale scores for the answers to many of the questions were not normally distributed; therefore, nonparametric methods were used to estimate $\mathrm{P}$ values when comparing scores. For most analyses, a Kruskal-Wallis ANOVA test was used. Ethics approval was granted by the University of Alberta Health Research Ethics Board (Edmonton, Alberta) and the ethics board of the Hôpital du Sacré-Coeur (Montreal, Quebec).

\section{RESULTS}

A total of 458 active adult pulmonologists in Canada were identified and contacted. A total of 209 questionnaires were returned, of which 201 contained useful data (44\%). The largest proportion of respondents ranged in age from 50 to 59 years $(36 \%)$, with one respondent younger than 30 years of age and two older than 70 years of age. The majority $(78 \%)$ were men. Most respondents (83\%) were Canadian medical graduates, with a smaller proportion being American (2\%) or international medical graduates (14\%). Respondents reported that they had seen a median of 10 patients (range one to 400 patients) in the previous year with work-related respiratory disease, and three cases (range 0 to 100 cases) of new-onset adult asthma caused by work in the previous year.

Median scores for the first question on initially considering occupational factors in the causation of new-onset adult asthma are shown in Figure 1. A trigger, such as having seen other workers affected at the same workplace or having encountered a previous case caused by the same agent, appeared to be the most important factor in initially considering occupation. The patient's opinion and the patient's report of undertaking a new job or work process appeared to be less important. The differences between the scores were statistically significant $(\mathrm{H}=82 ; \mathrm{P}<0.001$ [Kruskal-Wallis test]).

Median scores for answers to the second question regarding factors that would be important in strengthening the impression that asthma
- The patient's opinion that their asthma is work-related.

65.5

- Y ou know of others affected at the same workplace.

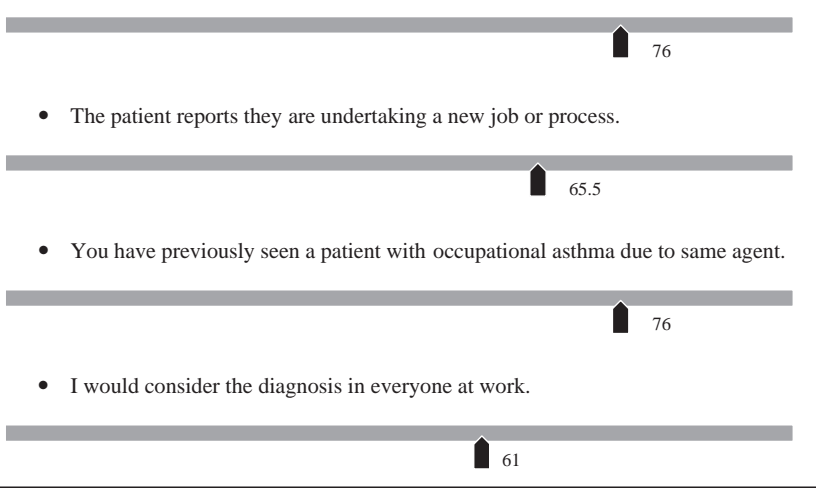

Figure 1) Median visual analogue scale scores for the question, 'When faced with a case of new-onset adult asthma, which of the following would make you consider occupational factors in the differential diagnosis?'

may be work related were the following: the patient reports worsening at work and improvement away from work (median score 86); the absence of any alternative causes such as a family history of atopy or a history of sensitization to common allergens (median score 59); and the patient was working with a known allergen (median score 87). The differences among the scores were, again, statistically significant $(\mathrm{H}=184 ; \mathrm{P}<0.001$ [Kruskal-Wallis test]).

Median scores for answers to the third question about significant barriers to considering a diagnosis of work-related asthma are shown in Figure 2. The score for the factor 'there is no benefit for patients in considering a diagnosis of work-related asthma' was considerably lower than scores for other answers. The differences between scores were statistically significant $(\mathrm{H}=446 ; \mathrm{P}<0.001$ [Kruskal-Wallis test]).

The fourth question asked about important barriers to diagnosing a case of work-related asthma. Median scores for the responses are shown in Figure 3. The response 'it is not useful to diagnose a patient's asthma as being work-related' scored much lower than the others. Once again, the differences among scores were statistically significant ( $\mathrm{H}=334 ; \mathrm{P}<0.001$ [Kruskal-Wallis test]).

The fifth question queried barriers to reporting a case of workrelated asthma to the WCB. Median scores for the responses are shown in Figure 4. The highest scores were for answers related to patient concerns regarding job security and income, and physicians' awareness of reporting requirements. Scores related to answers addressing additional paperwork and payment were lowest. Differences among the response scores were statistically significant $(\mathrm{H}=46 ; \mathrm{P}<0.001$ [Kruskal-Wallis test]).

The final question asked the participants for their opinions about which diagnostic tests they would use in addition to a symptom and work history before making a diagnosis of occupational asthma. Median scores for the possible answers were the following: tests confirming sensitization to a substance (eg, specific immunoglobulin E) (median score 71); tests showing a change in airway calibre with workplace exposure (eg, serial peak expiratory flow rate) (median score 83); tests showing a change in nonspecific airway responsiveness with workplace exposure (median score 83); and specific inhalation challenge (median score 86). Differences among the response scores were statistically significant $(\mathrm{H}=86 ; \mathrm{P}<0.001$ [Kruskal Wallis test]). Participants were also offered the option of suggesting additional tests not listed. Thirty-four participants suggested an additional test, the most common of which was induced sputum cytology, mentioned by 12 respondents. 


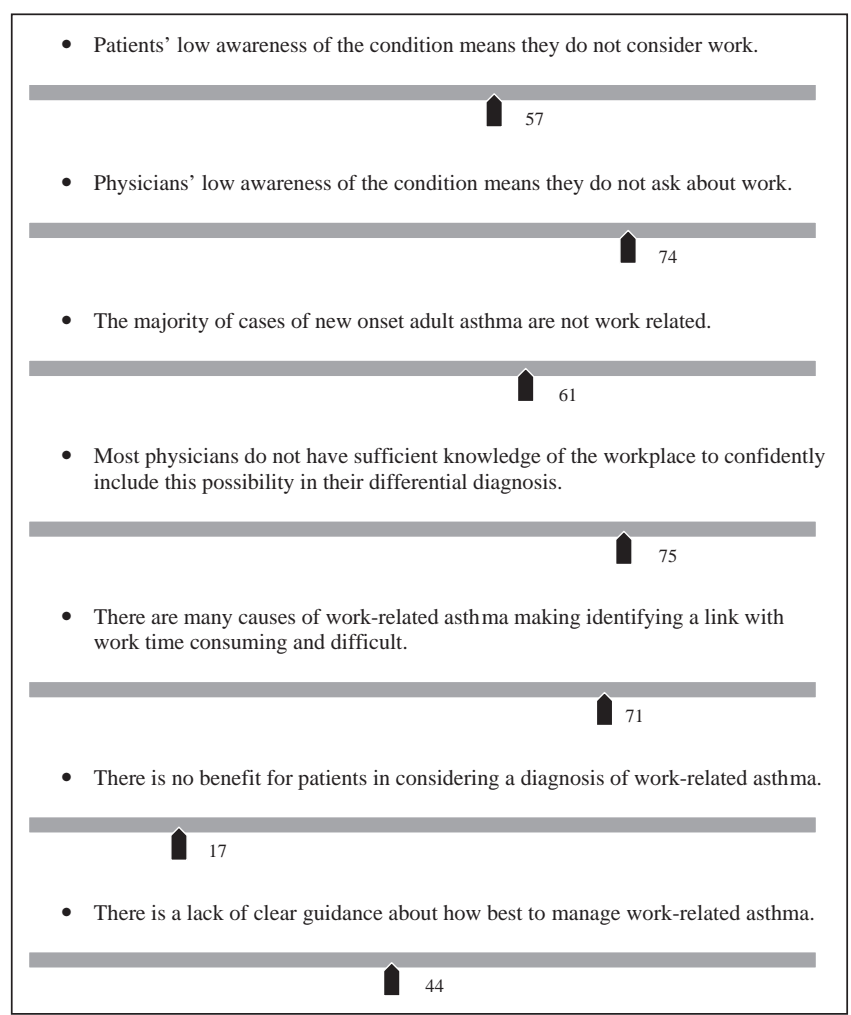

Figure 2) Median visual analogue scale scores for the question, 'Which of the following factors are significant barriers to considering a diagnosis of work-related asthma in an individual with new-onset adult asthma?'

- The lack of time in clinical .practice to obtain an accurate history of work-related changes in symptoms

- It is difficult to obtain a detailed work history and accurate information on
relevant workplace exposures.
- The complexity of the condition means it is difficult to diagnose with confidence.
- There is a lack of sensitive and/or specific tests for work-related asthma.
There is a lack of test facilities or referral centres where appropriate investigations
may be carried out.

Figure 3) Median visual analogue scale scores for the question, 'How much would you consider the following to be important barriers to diagnosing a case of work-related asthma?'

Most replies were received from Quebec $(n=57)$, Ontario $(n=47)$, British Columbia (BC) $(n=26)$ and Alberta $(A B)(n=24)$. Because some provinces had few respondents, responses were categorized as

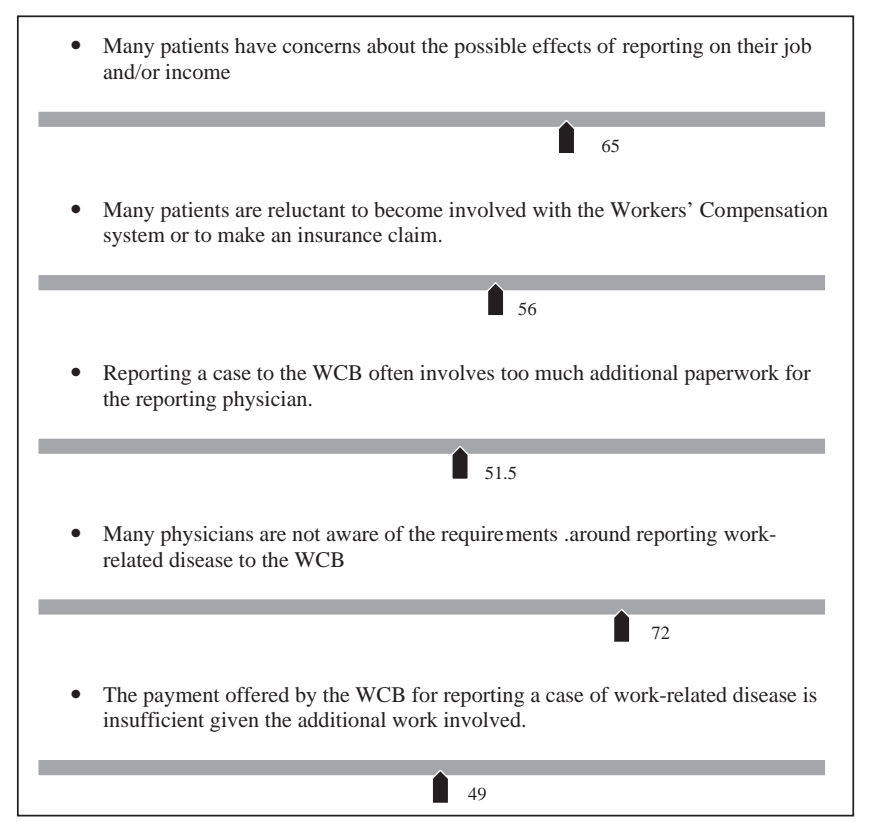

Figure 4) Median visual analogue scale scores for the question, 'How important are the following barriers to reporting a case of workrelated asthma to the Workers' Compensation Board?'

'Quebec', 'Ontario', 'AB and BC' or 'Others' for analysis according to province or region (Table 1 ). Broadly speaking, pulmonologists in Quebec scored the majority of the barriers to making a diagnosis lower than colleagues elsewhere, with marked differences in scores for the availability of specific tests and referral facilities. In addition, Quebec pulmonologists believed that the required paperwork was a less important barrier to reporting than other pulmonologists. When focusing on awareness of requirements concerning reporting, Ontario physicians scored lack of awareness as a more important barrier to reporting (median score 81) than Quebec, AB/BC and other parts of the country (median scores 63, 66 and 72, respectively). In considering the importance scores for different diagnostic tests, specific inhalation challenge was scored relatively high by pulmonologists from Ontario, $\mathrm{AB} / \mathrm{BC}$ and Other pulmonologists (median scores 84, 85 and 81, respectively), but was scored as very important by Quebec pulmonologists (median score 92) - a difference that was statistically significant.

No significant differences were seen in response scores according to age, sex, country of graduation or number of cases of work-related respiratory disease seen. However, the factor 'physicians are not aware of the requirements for reporting' was seen as a significantly greater barrier to reporting a case to the WCB for pulmonologists that encountered fewer cases of work-related respiratory disease $(\mathrm{P}<0.01)$.

\section{DISCUSSION}

The results of the present study highlight several issues important to ensuring the recognition and reporting of cases of work-related newonset adult asthma. First, physicians are most likely to consider work as a cause of asthma for an agent or situation with which they are already familiar. Given the large number of potential causes, it is likely that many physicians are only aware of the most common causes or those that they have previously encountered. In this situation, increased education and awareness regarding the potential causes of occupational asthma may be useful. The responses also suggest that physicians believed that the diagnosis of occupational asthma is a useful one, and that there is benefit for a patient in making the diagnosis.

Physicians noted a lack of time in practice to collect the sometimes complex information needed regarding symptoms and workplace exposures. This did not seem to stem from a perception that they were under rewarded or asked to complete too much paperwork, but 
TABLE 1

Factors with significant differences among provinces/regions regarding barriers to considering, diagnosing and reporting occupational asthma

\begin{tabular}{|c|c|c|c|c|}
\hline \multirow[b]{2}{*}{ Barrier } & \multirow[b]{2}{*}{ Region } & \multicolumn{2}{|c|}{ Visual analague scale score } & \multirow[b]{2}{*}{$\mathbf{P}^{*}$} \\
\hline & & Mean & Median (range) & \\
\hline Which of the following would be important in strengthening the impression that this may be work related? & & & & 0.026 \\
\hline \multirow[t]{4}{*}{ The patient is working with a known asthmagen } & $\mathrm{AB} / \mathrm{BC}$ & 87 & $91(60-99)$ & \\
\hline & Quebec & 83 & $84(56-100)$ & \\
\hline & Ontario & 87 & $89(32-100)$ & \\
\hline & Other & 85 & 88 (72-98) & \\
\hline
\end{tabular}

Which of the following are significant barriers to considering occupational asthma in the diagnosis? The majority of new-onset adult asthma is not work related

\begin{tabular}{|c|c|c|c|}
\hline $\mathrm{AB} / \mathrm{BC}$ & 62 & $64(2-99)$ & 0.003 \\
\hline Quebec & 50 & $50(4-92)$ & \\
\hline Ontario & 62 & $62(11-95)$ & \\
\hline Other & 66 & $67(38-94)$ & \\
\hline $\mathrm{AB} / \mathrm{BC}$ & 69 & 67 (24-99) & 0.004 \\
\hline Quebec & 68 & 73 (5-97) & \\
\hline Ontario & 79 & 79 (45-98) & \\
\hline Other & 78 & $78(55-94)$ & \\
\hline $\mathrm{AB} / \mathrm{BC}$ & 67 & $71(1-96)$ & 0.011 \\
\hline Quebec & 58 & $63(0-95)$ & \\
\hline Ontario & 71 & 75 (13-100) & \\
\hline Other & 67 & $70(25-94)$ & \\
\hline $\mathrm{AB} / \mathrm{BC}$ & 63 & 65 (16-99) & 0.004 \\
\hline Quebec & 50 & $54(0-86)$ & \\
\hline Ontario & 59 & $67(9-94)$ & \\
\hline Other & 71 & 76 (29-95) & \\
\hline $\mathrm{AB} / \mathrm{BC}$ & 70 & 73 (16-98) & 0.000 \\
\hline Quebec & 43 & $41(4-92)$ & \\
\hline Ontario & 60 & 65 (18-95) & \\
\hline Other & 79 & $80(42-96)$ & \\
\hline $\mathrm{AB} / \mathrm{BC}$ & 65 & $72(2-98)$ & 0.000 \\
\hline Quebec & 40 & 32 (0-97) & \\
\hline Ontario & 64 & 73 (0-98) & \\
\hline Other & 73 & 81 (31-94) & \\
\hline $\mathrm{AB} / \mathrm{BC}$ & 53 & 51 (4-99) & 0.003 \\
\hline Quebec & 41 & $38(0-97)$ & \\
\hline Ontario & 61 & $67(0-98)$ & \\
\hline Other & 65 & 66 (15-98) & \\
\hline $\mathrm{AB} / \mathrm{BC}$ & 62 & $66(13-100)$ & 0.001 \\
\hline Quebec & 60 & $63(3-94)$ & \\
\hline Ontario & 75 & $81(0-99)$ & \\
\hline Other & 64 & $72(20-97)$ & \\
\hline $\mathrm{AB} / \mathrm{BC}$ & 52 & $52(6-100)$ & 0.010 \\
\hline Quebec & 41 & $39(0-94)$ & \\
\hline Ontario & 55 & $51(0-99)$ & \\
\hline Other & 66 & 64 (19-98) & \\
\hline $\mathrm{AB} / \mathrm{BC}$ & 78 & $85(8-100)$ & 0.006 \\
\hline Quebec & 88 & $92(47-100)$ & \\
\hline Ontario & 75 & $84(13-100)$ & \\
\hline Other & 73 & 81 (6-99) & \\
\hline
\end{tabular}

How important are the following barriers to diagnosing a case of work-related asthma? It is difficult to obtain a detailed work history and accurate information on relevant exposures

The complexity of the condition makes it difficult to diagnose

There is a lack of sensitive and specific tests

There is a lack of test facilities or referral centres

How important are the following barriers to reporting a case of work-related asthma to the WCB? Reporting a case to the WCB requires too much additional paperwork

Many physicians are not aware of requirements around reporting

The payment offered by the WCB for reporting a case is insufficient given the extra work involved

Which tests would you like to use in addition to a symptom and work history? Specific inhalation challenge

${ }^{\star}$ Kruskal-Wallis test. AB Alberta; BC British Columbia; WCB Workers' Compensation Board

rather that time constraints simply did not allow sufficient time for the detailed work required. A similar finding was reported for both specialists and family physicians in Ontario when dealing with workrelated asthma and contact dermatitis $(13,14)$. In these studies, time constraints were most frequently identified by pulmonologists and family physicians as a barrier to taking a history of workplace exposure, and were the third most frequently reported by dermatologists. In the same reports, the barrier to taking a work history most frequently reported by dermatologists was a lack of knowledge about the workers' compensation system (14). Results from our study suggested that a lack of knowledge about requirements for reporting were important. An additional study (15) identified time and knowledge constraints as the main barriers to recognizing occupational disease among American and Mexican physicians. Our study also identified that physicians believed that their patients with occupational asthma were worried about the possible impact it would have on their job and income, and that this 
constituted a barrier to reporting. In terms of the tests that the participants believed to be useful in addition to a symptom and work history, relatively high scores were given to most types of additional testing, although tests for sensitization scored lower than others. This may be a recognition of the fact that a specific immunoglobulin E or skin prick test may not be available to confirm many forms of occupational asthma, particularly those caused by low-molecular-weight agents.

Quebec pulmonologists scored many of the barriers to recognizing occupational asthma lower than pulmonologists in other parts of Canada. This difference may be due to a greater recognition of the diagnosis in Quebec. In addition, pulmonologists from Quebec believed that the specific inhalation challenge was a more important test than respondents in other regions of Canada. The requirements of the different compensation systems and the financial compensation offered to each diagnosed patient may be important factors explaining the number of cases diagnosed, the type of investigation performed and the availability of diagnostic tests in each province. For example, a specific inhalation challenge test is almost always required for acceptance of a WCB claim for occupational asthma in Quebec and, generally, is readily available. For pulmonologists outside of Quebec, a specific inhalation challenge test is usually not required for WCB purposes, and is often not readily available. Pulmonologists practicing in Quebec were also less likely to believe that the complexity of the condition and lack of testing or referral centres were barriers to diagnosis.

The present study has several limitations. First, the response rate was relatively low; therefore, the potential for response bias exists. For example, physicians with a greater interest in occupational asthma may have been more likely to respond, which may have led to an optimistic assessment of how much physicians believed they knew about this topic. All of our participants reported seeing some cases of workrelated respiratory disease in the previous year, but not all had seen a case of work-related new-onset adult asthma, suggesting that only those who were already most involved and interested responded. Also, it seems unlikely that such a bias would cause respondents to report that lack of knowledge or awareness was an important issue, which we found. However, it may have affected scores for items related to the usefulness of the diagnosis or whether patients benefit from the diagnosis. Second, for some items, we asked physicians to comment on what they thought their patients believed or experienced. Clearly, their perceptions may have been inaccurate but, nonetheless, it is the physician's perception of the patient's opinion that would likely influence the physician's willingness to report and, hence, we believe this opinion remains relevant. A previous study that investigated patients' reasons for delaying discussion with a physician about potential symptoms of occupational asthma (16) identified fear of losing time at work, and fear of forced job loss or job change as important causes of delay. In addition, we realized during the course of the research that some of the questions could be interpreted as asking physicians their opinions of what other physicians believed because the questions did not specifically ask for the physicians' own opinion. No participant in the study commented on this potential ambiguity when responding to the questionnaire, nor was it raised as an issue during our initial piloting of the questionnaire. While we do not believe this had a large impact on the way participants answered the questions, we cannot be completely sure. Finally, our questionnaire used closed rather than open-ended questions. We carefully considered the questions we used and the available range of responses; however, by limiting the participants' range of responses, we may have missed important information. This does not, however, diminish the significance of the information that we have presented.

\section{SUMMARY}

It appears that pulmonologists most readily diagnose occupational asthma when it occurs in response to an agent or workplace situation with which they are familiar. They believed that time constraints and limited knowledge of the workplace and about workplace exposures hamper their ability to recognize occupational asthma. They believed that their patients were concerned about reporting cases because of the potential impact it would have on their job and income, which, consequently, discourages them from reporting. In addition, they believed that physicians may not always be fully aware of the requirements for reporting. Nonetheless, they believed that occupational asthma is a useful diagnosis to make and of benefit to the patient.

ACKNOWLEDGEMENTS: Role of each author: Anu Parhar mailed questionnaires, received responses, entered data, performed initial analyses, and assisted in preparing and editing the manuscript. Catherine Lemiere contributed to the study design, obtained data from Collège des médecins de Quebec, gained ethics approval, and assisted in preparing and editing the manuscript. Jeremy $\mathrm{R}$ Beach contributed to the study design, gained ethics approval, mailed questionnaires and received responses, entered additional data, performed the final analyses, and took the lead role in preparing and editing the manuscript.

\section{APPENDIX 1}

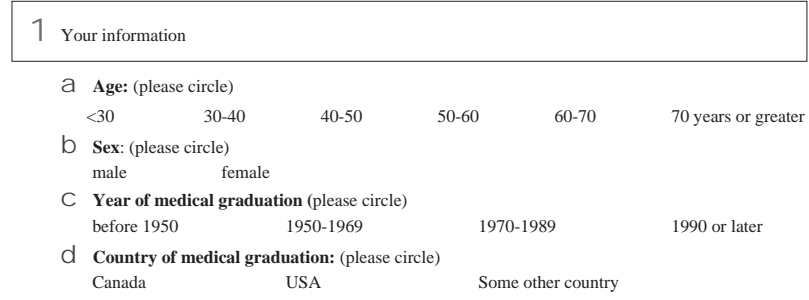

2 A pproximately how many cases of work-related respiratory disease have you seen in the past year?

3 A pproximately how many cases of new onset adult asthma caused by work have you seen in the past year? (Please do not include existing cases of asthma who have simply had symptoms triggered at work.)

4 A pproximately what percentage of these do you believe were due to allergic occupational asthma and how many were due to non allergic occupational asthma?

\begin{tabular}{|c|c|c|}
\hline$\%$ Allergic & $\%$ Non allergic (i.e. irritant or RADS) & Total \\
\hline$\%$ & $\%$ & $100 \%$ \\
\hline
\end{tabular}

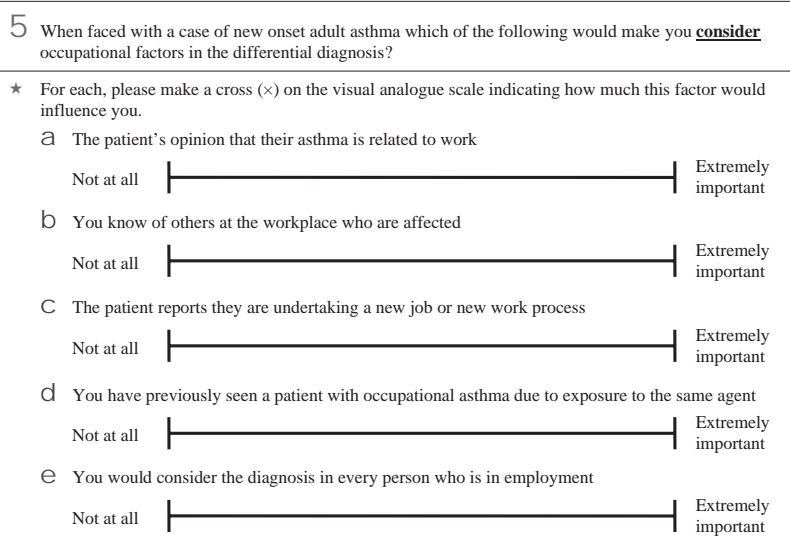

continued on next page 


\section{APPENDIX 1 - CONTINUED}

6 Which of the following factors would be important in strencthening the impression that this might be work-related?

a The patient reports a symptom pattern with worsening at work and improvement away from work. Not at all

b The absence of any alternative cause such as a family history of atopy or a history of sensitization to common environmental allergens.

Not at all

C The patient is working with a known asthmagen.

Notat all $\longmapsto \mid \begin{aligned} & \text { Extremely } \\ & \text { important }\end{aligned}$

7 Which of the following factors are significant barrierstoconsidering a diagnosis of work-related asthma in an individual with new onset adult asthma?

a Patients' low awareness of the condition means they do not consider the possible role of work. \begin{tabular}{l|l} 
Not at all & $\begin{array}{l}\text { Extremely } \\
\text { important }\end{array}$
\end{tabular}

b Physicians' low awareness of the condition means they do not ask about work. \begin{tabular}{l|l} 
Not at all $\longmapsto$ & $\begin{array}{l}\text { Extremely } \\
\text { important }\end{array}$
\end{tabular}

C The majority of cases of new onset adult asthma are not work-related. Not at all $\longmapsto \mid \begin{aligned} & \text { Extremely } \\ & \text { important }\end{aligned}$

d M ost physicians do not have a sufficient knowledge of work processes and exposures to confidently include this possibility in their differential diagnosis.

\begin{tabular}{l|l|l} 
Not at all & $\begin{array}{l}\text { Extremely } \\
\text { important }\end{array}$
\end{tabular}

e There are many causes of work-related asthma which makes identifying a link with the workplace time consuming and difficult.

Not at all

f There is no benefit for patients in considering a diagnosis of work-related asthma. Notat all

g There is a lack of clear guidance about how best to manage a patient with work-related asthma \begin{tabular}{l|l} 
Not at all $\longmapsto$ & $\begin{array}{c}\text { Extremely } \\
\text { important }\end{array}$
\end{tabular}

8 How much would you consider the following to be important barrierstodiacnosing a case of workrelated asthma?

a The lack of time in clinical practice to obtain an accurate history of work-related changes in symptoms. Not at all

b It is difficult to obtain a detailed work history and accurate information on relevant workplace exposures. Notat all

C The complexity of the condition means that it is difficult to diagnose with confidence. Notat all

d There is a lack of sensitive and/or specific tests for work-related asthma. Notat all

e There is a lack of test facilities or referral centres where appropriate investigations may be carried out. Not at all

f It is not useful to diagnose a patient's asthma as being work-related. Not at all
9 How much are the following important barrierstoremortinga case of work-related asthma to the W orkers' Compensation B oard or equivalent agency?

a M any patients have concerns about the possible effects of reporting on their job and/or income. Not at all $\longmapsto \mid \begin{aligned} & \text { Extremely } \\ & \text { important }\end{aligned}$

b M any patients are reluctant to become involved with the Workers' Compensation system or to make an insurance claim.

Not at all $\longmapsto \mid \begin{aligned} & \text { Extremely } \\ & \text { important }\end{aligned}$

C Reporting a case to the WCB often involves too much additional paperwork for the reporting physician. Not at all $\longmapsto$

d M any physicians are not aware of the requirements around reporting work-related disease to the WCB Not at all

e The payment offered by the WCB for reporting a case of work-related disease is insufficient given the additional work involved.

Not at all $\longmapsto \mid \begin{aligned} & \text { Extremely } \\ & \text { important }\end{aligned}$

10 which of the tests listed below would you wish to use in addition to a symptom and work history before making a diagnosis of occupational asthma?

a Tests confirming sensitization to a substance encountered in the workplace (e.g. specific IgE, skin prick test)

\begin{tabular}{l|l} 
Not at all & $\begin{array}{l}\text { Extremely } \\
\text { important }\end{array}$
\end{tabular}

b Tests showing a change in airway caliber with workplace exposure (e.g. serial PEFR)

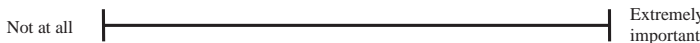

C Tests showing a change in non-specific airway responsiveness with workplace exposure Not at all $\longmapsto$

d Specific inhalation challenge Not at all $\longmapsto \mid \begin{aligned} & \text { Extremely } \\ & \text { important }\end{aligned}$

e Other (please specify): Not at all

11 A re you willing to participate in discussion about the establishment of a databank or biobank for collecting information on new cases of occupational asthma?

\section{YES $\quad$ NO}

If yes, how would you prefer this discussion takes place: (please circle preferred option)

$\begin{array}{lll}\begin{array}{l}\text { E-mail discussion } \\ \text { group }\end{array} & \text { Phone/ } & \text { In person at local/ } \\ \text { teleconference } & \text { national meetings }\end{array}$

Please indicate your preferred contact details below if you are willing to participate

Name:

Phone number:

E-mail address:

Address:

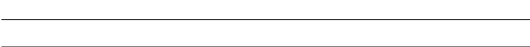

\section{REFERENCES}

1. Hill AB. The environment and disease: Association or causation. Proc R Soc Med 1965;58:295-300.

2. Hennekens $\mathrm{CH}$, Buring JE. Statistical association and cause effect relationships. In: Mayrent SL, ed. Epidemiology in Medicine. Boston: Little Brown and Company, 1987:30-53.

3. Rothman KJ, Greenland S. Causation and causal inference. In: Rothman KJ, Greenland S, eds. Modern Epidemiology, 2nd edn. Philadelphia: Lippincott Raven, 1998:7-28.

4. Muir DC. Cause of occupational disease. Occup Environ Med 1995;52:289-93.

5. Ozonoff D. Medical and legal causation. Ann N Y Acad Sci 1989;572:23-6

6. Teschke K, Barroetavena MC. Occupational cancer in Canada: What do we know? Can Med Assoc J 1992;147:1501-7.
7. Pichora EC, Payne JI. Trends and characteristics of compensated occupational cancer in Ontario, Canada, 1937-2003.

Am J Ind Med 2007;50:980-91.

8. Chen Y, Agius R, McMamee R, et al. Physicians' beliefs in the assessment of work attribution when reporting musculoskeletal disorders. Occup Med 2005;55:298-307.

9. Kogevinas M, Zock JP, Jarvis D, et al. Exposure to substances in the workplace and new-onset asthma: An international prospective population-based study (ECRHS-II). Lancet 2007;370:336-41.

10. Torén K, Blanc PD. Asthma caused by occupational exposures is common - a systematic analysis of estimates of the population-attributable fraction. BMC Pulm Med 2009;9:7.

11. Beach J, Rowe BH, Blitz S, et al. Evidence Report/Technology assessment No. 129. Diagnosis and management of work-related 


\section{Parhar et al}

asthma. AHRQ Publication No. 06-E003-2. Rockville: Agency for Healthcare Research and Quality, 2005.

12. Cherry NM, Beach J, Burstyn I, et al. Data linkage to estimate the extent and distribution of occupational disease: New onset adult asthma in Alberta, Canada. Am J Ind Med 2009;52:831-40.

13. Holness DL, Tabassum S, Tarlo SM, et al. Practice patterns of pulmonologists and family physicians for occupational asthma. Chest 2007;132:1526-31.
14. Holness DL, Tabassum S, Tarlo SM, et al. Dermatologist and family practitioner practice patterns for occupational contact dermatitis. Australas J Dermatol 2007;48:22-7.

15. Harber P, Merz B. Time and knowledge barriers to recognizing occupational disease. J Occup Environ Med 2001;43:285-8.

16. Poonai N, van Diepen S, Bharatha A, et al. Barriers to diagnosis of occupational asthma in Ontario. Can J Public Health 2005;96:230-3. 


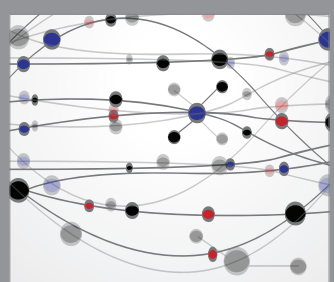

The Scientific World Journal
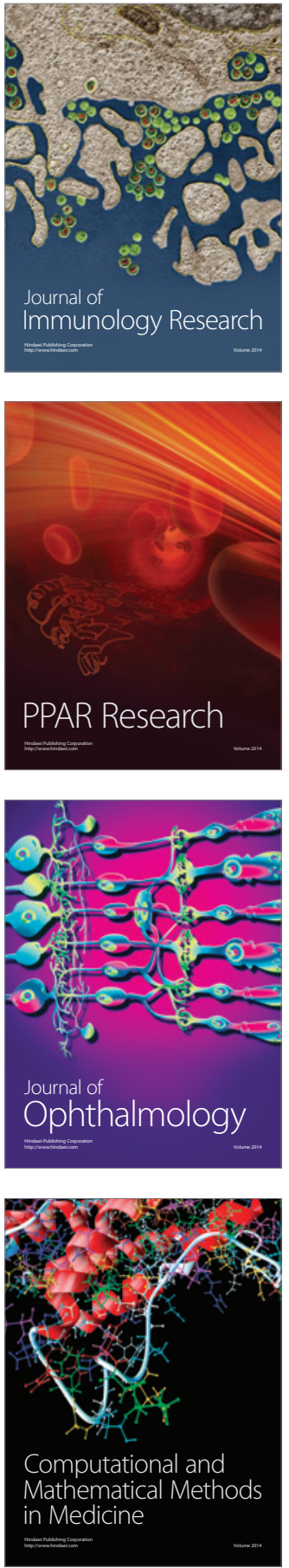

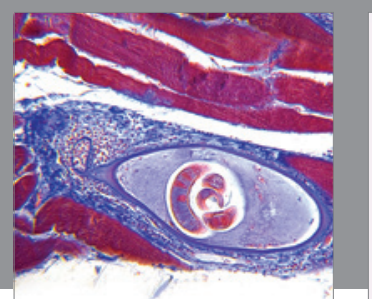

Gastroenterology Research and Practice

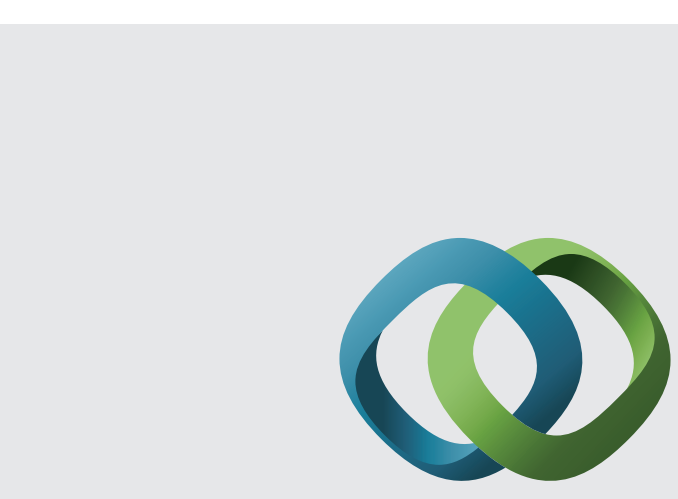

\section{Hindawi}

Submit your manuscripts at

http://www.hindawi.com
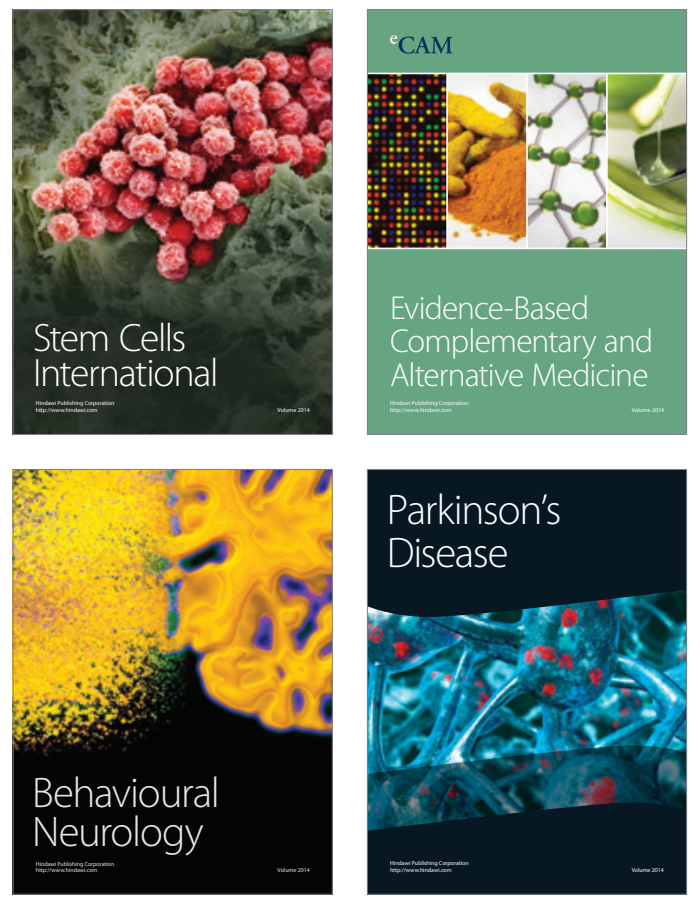
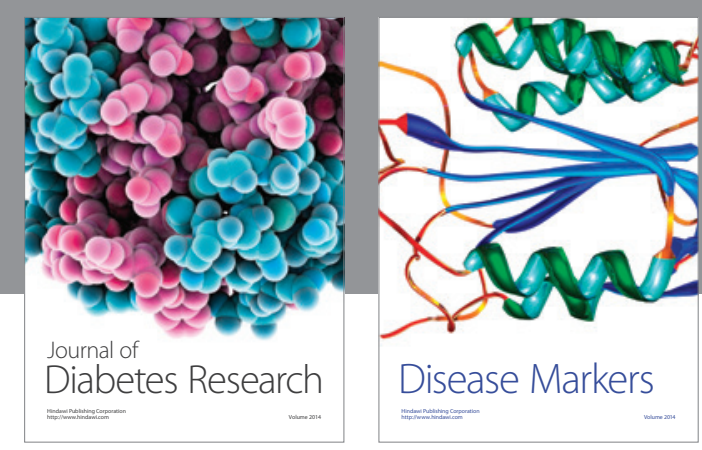

Disease Markers
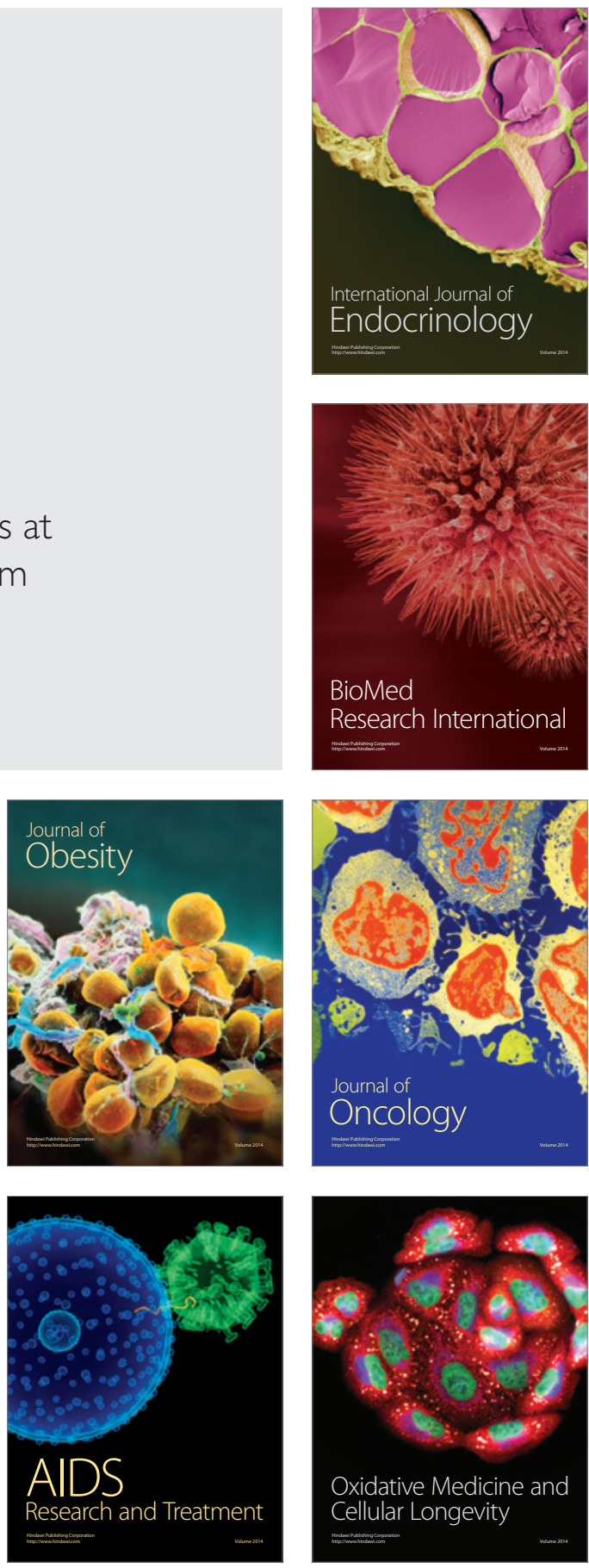